DOI: 10.1002/cbic.200500532

\section{Monitoring Chemical Reactions by Using lon-Channel-Forming Peptides}

\author{
Steven Blake, ${ }^{[a]}$ Thomas Mayer, ${ }^{[b]}$ Michael Mayer, ${ }^{*[b]}$ \\ and Jerry Yang*[a]
}

This paper presents a method for monitoring chemical reactions on individual molecules. We exploit the functional properties of an ion-channel-forming peptide to follow the conversion of chemical groups on molecules attached near the opening of these semisynthetic nanopores. It is known that the conductance properties of derivatives of gramicidin $\mathrm{A}(\mathrm{gA})$ can be measurably different. ${ }^{[1]}$ Here, we take advantage of singlechannel conductance measurements to monitor in situ the multistep conversion of a tert-butyloxycarbonyl-protected (Boc-protected) amine to the free amine and the subsequent diazotization/hydrodediazoniation of the amine to an alcohol functionality on molecules attached to gA. These model reactions show that $\mathrm{gA}$ provides a simple nanoscale platform for sensing external chemical reagents with high sensitivity and selectivity.

Gramicidin A is a natural ion-channel-forming peptide (molecular weight $1.9 \mathrm{kDa}$, secreted from the bacterium Bacillus brevis) that incorporates into lipid bilayers and facilitates the transmembrane flux of monovalent cations upon reversible dimerization in bilayers (Figure $1 \mathrm{~A}$ ). ${ }^{[2]}$ Although several artificial ion channels based on genetically engineered proteins, ${ }^{[3]}$ peptides, $^{[4]}$ or oligomers of organic molecules ${ }^{[5]}$ have been explored for their potential use as chemo- and biosensors, ${ }^{[6]}$ most of these sensors are designed to sense particular structural properties of chemical or biochemical species (such as the ability of a ligand to interact with a binding pocket). In this work, we explore the use of ion channels derived from gA to detect chemicals that display particular functional properties (such as the ability to facilitate specific chemical transformations). Bayley and co-workers have previously demonstrated that wild-type and genetically modified $\alpha$-hemolysin (a 232.4 kDa protein ${ }^{[7]}$ ) can be used to monitor the conversion of a light-driven reaction by recording distinct conductances of intermediates throughout the course of the reaction. ${ }^{[3 c]}$ Here, we demonstrate that it is possible to monitor the synthetic conversion of reactive chemical groups on molecules attached

[a] S. Blake, Prof. J. Yang

Department of Chemistry and Biochemistry

University of California, San Diego

9500 Gilman Drive, MC 0358, La Jolla, CA 92093-0358 (USA)

Fax: (+ 1) 858-534-4554

E-mail:jyang@chem.ucsd.edu

[b] T. Mayer, Prof. M. Mayer

Department of Biomedical Engineering and

Department of Chemical Engineering, University of Michigan

2200 Bonisteel Boulevard, Ann Arbor, MI 48109-2099 (USA)

Fax: (+1) 734-763-4371

E-mail:mimayer@umich.edu

Supporting information for this article is available on the WWW under http://www.chembiochem.org or from the author.
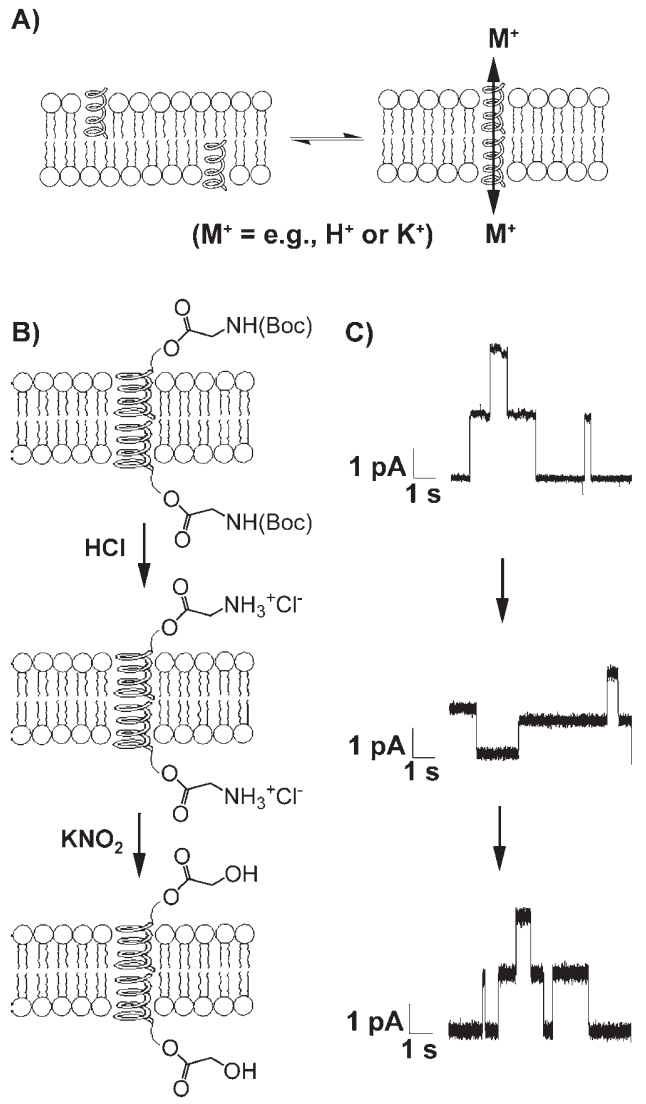

Figure 1. Monitoring chemical reactions on molecules attached to gramici$\operatorname{din} \mathrm{A}(\mathrm{gA})$ by analysis of single ion-channel currents. A) Cartoon of the reversible dimerization of $\mathrm{gA}$ in lipid bilayers. B) Illustration of the stepwise conversion of gA carrying a Boc-protected glycine group (top) to gA carrying a glycolic acid group (bottom) in the presence of external reagents. C) Representative single ion-channel recordings (in $1 \mathrm{~m} \mathrm{KCl}, 0.01 \mathrm{~m}$ HEPES buffer, $\mathrm{pH}$ 7.4) of the corresponding derivatives of $\mathrm{gA}, \mathbf{1 - 3}$, shown in part (B).

to gA in the presence of external chemical reagents in solution to afford identifiable and isolatable products with measurably different single-channel conductance. This research extends the pioneering work on $\alpha$-hemolysin to a synthetically accessible platform-gA - that is readily available in high purity and in useful quantities.

We synthesized and characterized derivatives of $\mathrm{gA}$ carrying $\mathrm{N}$-Boc-protected glycine (1), glycine (2), and glycolic acid (3) moieties attached to the $C$ terminus of commercially available gA (Figure 1B). The Supporting Information summarizes the details of the syntheses. We measured the single-channel current of 1-3 by incorporating them into planar lipid bilayers. Figure $1 \mathrm{C}$ shows representative current-versus-time traces of 1-3 under an applied potential of $100 \mathrm{mV}$ in buffered solution $(1 \mathrm{M} \mathrm{KCl}, 0.01 \mathrm{~m}$ HEPES buffer, $\mathrm{pH}$ 7.4). These traces show that the conductance of ions through derivatives 1-3 was dependent on the functional group present on the $\mathrm{C}$ terminus. Analysis of the current-versus-potential curves (Figure S1 in the Supporting Information) reveals a distinct single-channel conductance of $22.3 \pm 0.2,13.5 \pm 0.8$, and $19.6 \pm 0.5 \mathrm{pS}$ for derivatives $\mathbf{1 - 3}$, respectively. The measurably different conductance properties of these derivatives made it possible to monitor the 
interconversion of 1-3 upon addition of external chemical reagents in an aqueous environment.

The deprotection of Boc groups on amines is commonly achieved under acidic conditions. ${ }^{[8]}$ We added 1 to a final concentration of $50 \mathrm{pm}$ to both $1.0 \mathrm{~mL}$ chambers of a stirred planar lipid bilayer setup ${ }^{[9]}$ containing unbuffered solutions of $0.5 \mathrm{M} \mathrm{HCl}$ and $0.5 \mathrm{M} \mathrm{KCl}$ and monitored the ion-channel activity after approximately $10 \mathrm{~min}$. Initially, the main single-channel current at a potential of $100 \mathrm{mV}$ was $19.0 \pm 0.9 \mathrm{pA}$ (corresponding to a single-channel conductance of $190 \pm 9 \mathrm{pS}$ ) as indicated by the histogram in Figure $2 \mathrm{~B}^{\left[{ }^{10]}\right.}$ After $30 \mathrm{~min}$, the occurrence of the single-channel current value of $19.0 \mathrm{pA}$ was significantly
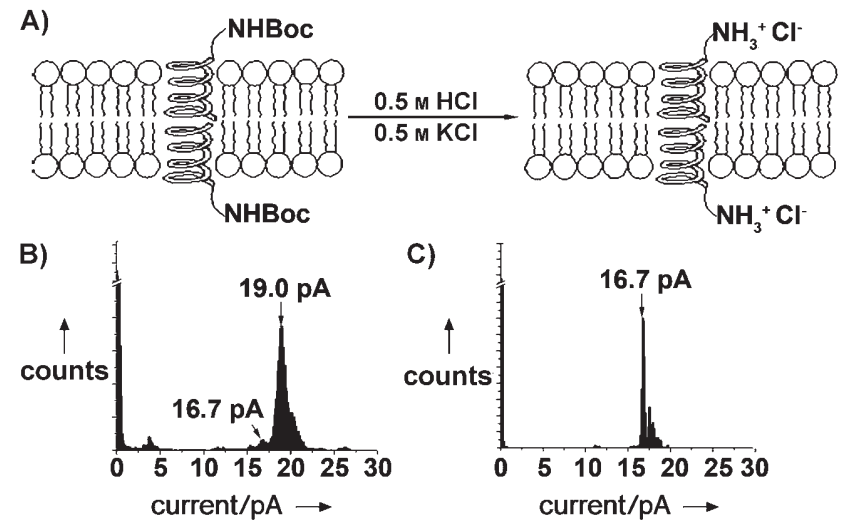

Figure 2. Monitoring of the single ion-channel currents during the conversion $\mathrm{gA}$ derivative $\mathbf{1}$ to $\mathrm{gA}$ derivative $\mathbf{2}$. A) Illustration of the removal of a tert-butyloxycarbonyl group from an amine under aqueous acidic conditions. Histograms of the observed single-channel current states of 1 recorded B) $10 \mathrm{~min}$ and C) $60 \mathrm{~min}$ after initiating the reaction shown in (A).

reduced and after an additional $30 \mathrm{~min}$ ( $60 \mathrm{~min}$ total after introduction of 1 ), the main single-channel current observed was at $16.7 \pm 0.3 \mathrm{pA}$ (Figure $2 \mathrm{C}$ ). ${ }^{[11]}$ We independently measured a current of $17.1 \pm 0.3 \mathrm{pA}$ for 2 under the same conditions (i.e., $0.5 \mathrm{M} \mathrm{KCl}$ and $0.5 \mathrm{M} \mathrm{HCl}$ ), which is consistent (within experimental error) with the final current value of $16.7 \pm 0.3 \mathrm{pA}$ recorded for the deprotection of the $\mathbf{1}$ in aqueous acidic solution. We attribute the smaller single-channel conductance of $\mathbf{2}$ compared to 1 to the presence of a positive charge on the deprotected amine of $\mathbf{2}$ (as opposed to the electroneutral character of $\mathbf{1}$ ). A positive charge close to the opening of the channel presumably reduces the permeability of monovalent cations through 2 compared to $1 .^{[1 \mathrm{~d}]}$ We confirmed by ${ }^{1} \mathrm{H}$ NMR spectroscopy that $1 \mathrm{~mm} \mathrm{~N}$-Boc-protected glycine is deprotected within $80 \mathrm{~min}$ under analogous conditions in $\mathrm{D}_{2} \mathrm{O}$.

To demonstrate further the possibility of following the transformation of functional groups on molecules attached to gA, we monitored the conversion of the free amine on the C-terminally linked glycine moiety of $\mathbf{2}$ (i.e., the product of the reaction of 1 with $\mathrm{HCl}$ ) to an alcohol group in the presence of potassium nitrite under aqueous acidic conditions. ${ }^{[12]}$ We recorded a single ion-channel current of $1.4 \pm 0.1 \mathrm{pA}$ for 2 (final concentration 20 рм) in a stirred planar lipid-bilayer setup contain- ing $0.1 \mathrm{~m} \mathrm{KCl}$ and $0.5 \mathrm{~m}$ potassium acetate buffer $(\mathrm{pH} 3.8)$ at a potential of $100 \mathrm{mV}$. We added $\mathrm{KNO}_{2}$ to both chambers of the planar lipid-bilayer setup (to give a final concentration of $0.03 \mathrm{M} \mathrm{KNO}_{2}$ in each chamber) and monitored the ion-channel activity. After approximately $45 \mathrm{~min}$, we recorded a singlechannel current value of $1.8 \pm 0.1 \mathrm{pA}$. Independent measurement of $\mathbf{3}$ under the same experimental conditions gave a single ion-channel current of $1.8 \pm 0.1 \mathrm{pA}$, which was consistent with the results from monitoring the conversion of $\mathbf{2}$ to $\mathbf{3}$ by single ion-channel recordings. As expected, the conversion of the positively charged amine in $\mathbf{2}$ to the electroneutral alcohol in $\mathbf{3}$ resulted in higher single-channel conductance of $\mathbf{3}$ compared to $\mathbf{2}$ (due to the presumed increased permeability of monovalent cations through 3). For comparison, we observed by ${ }^{1} \mathrm{H}$ NMR spectroscopy that $0.01 \mathrm{~m}$ glycine can be converted quantitatively to glycolic acid within $60 \mathrm{~min}$ in the presence of $0.3 \mathrm{~m}$ nitrite under similar buffered conditions in $\mathrm{D}_{2} \mathrm{O}$.

We have, thus, demonstrated the possibility of following the conversion of chemically reactive groups on derivatives of $\mathrm{gA}$ in the presence of external chemical reagents by monitoring single ion-channel currents. ${ }^{[13]}$ This approach to the use of ionchannel-forming peptides as chemical sensors complements studies on fluorescent chemosensors, ${ }^{[14]}$ which monitor changes in the local environment of a molecule (here, manipulating the charge of functional groups near the opening of an ion-channel pore) to sense a chemical process. Further development of ion-channel-forming molecules with synthetically tailored conductance properties might make it possible to detect a wide range of chemically and biochemically active agents in solution with high sensitivity and selectivity. Synthetically tailored ion channels might also be useful for fundamental studies of organic reactions on molecules embedded in bilayers for cell-surface engineering applications. ${ }^{[15]}$

\section{Acknowledgements}

This work was partially supported by the Academic Senate, the Faculty Career Development Program, and Department of Chemistry and Biochemistry at UCSD. We thank Michael J. Doornbos for the initial recordings of ion-channel currents. T.M. and M.M. acknowledge support from an NSF CAREER Award.

Keywords: biotechnology · gramicidin A - membranes · selfassembly $\cdot$ sensors

[1] a) H.-J. Apell, E. Bamberg, P. Lauger, Biochim. Biophys. Acta 1979, 552, 369-378; b) E. Bamberg, H.-J. Apell, H. Alpes, P. Lauger in Peptides: Structure and Biological Function, Vol. 6 (Eds.: E. Gross, J. Meienhofer), Pierce Chemical Company, Rockford, 1979, p.629-634; c) K. Janko, R. Reinhardt, H.-J. Apell, H. Alpes, P. Lauger, E. Bamberg, Peptides: Structure and Function, Vol. 8 (Eds.: V. J. Hruby, D. H. Rich), Pierce Chemical Company, Rockford, 1983, 463-472; d) G. A. Wooley, A. S. I. Jalkaran, Z. Zhang, S. Peng, J. Am. Chem. Soc. 1995, 117, 4448-4454.

[2] D. J. Aidley, P. R. Stanfield, Ion Channels: Molecules in Action, Cambridge University Press, Cambridge, 1996.

[3] a) S. H. Shin, T. Luchian, S. Cheley, O. Braha, H. Bayley, Angew. Chem. 2002, 114, 3859-3861; Angew. Chem. Int. Ed. 2002, 41, 3707-3709; b) S. H. Shin, H. Bayley, J. Am. Chem. Soc. 2005, 127, 10462-10463; c) T. Luchian, S. H. Shin, H. Bayley, Angew. Chem. 2003, 115, 1970-1973; 
Angew. Chem. Int. Ed. 2003, 42, 1926-1929; d) S. Howorka, S. Cheley, H. Bayley, Nat. Biotechnol. 2001, 19, 636-639; e) S. Howorka, J. Nam, H. Bayley, D. Kahne, Angew. Chem. 2004, 116, 860-864; Angew. Chem. Int. Ed. 2004, 43, 842-846; f) L. Q. Gu, O. Braha, S. Conlan, S. Cheley, H. Bayley, Nature 1999, 398, 686-690; g) N. Ashkenasy, J. Sanchez-Quesada, H. Bayley, M. R. Ghadiri, Angew. Chem. 2005, 117, 1425-1428 Angew. Chem. Int. Ed. 2005, 44, $1401-1404$.

[4] a) D. Bali, L. King, S. Kim, Aust. J. Chem. 2003, 56, 293-300; b) T. D. Clark L. K. Buehler, M. R. Ghadiri, J. Am. Chem. Soc. 1998, 120,651-656; c) T. Lougheed, V. Borisenko, T. Hennig, K. Ruck-Braun, G. A. Woolley, Org. Biomol. Chem. 2004, 2, 2798-2801; d) T. Lougheed, Z. H. Zhang, G. A Woolley, V. Borisenko, Bioorg. Med. Chem. 2004, 12, 1337-1342; e) V. Borisenko, Z. H. Zhang, G. A. Woolley, Biochim. Biophys. Acta 2002, 1558 26-33; f) S. Futaki, Y. J. Zhang, T. Kiwada, I. Nakase, T. Yagami, S. Oiki, Y. Sugiura, Bioorg. Med. Chem. 2004, 12, 1343-1350; g) S. Terrettaz, W. P. Ulrich, R. Guerrini, A. Verdini, H. Vogel, Angew. Chem. 2001, 113, $1790-$ 1793; Angew. Chem. Int. Ed. 2001, 40, 1740-1743; h) B. A. Cornell, V. L. B. Braach Maksvytis, L. G. King, P. D. J. Osman, B. Raguse, L. Wieczorek, R. J. Pace, Nature 1997, 387, 580-583.

[5] a) N. Sakai, S. Matile, J. Am. Chem. Soc. 2002, 124, 1184-1185; b) G. W. Gokel, P. H. Schlesinger, N. K. Djedovic, R. Ferdani, E. C. Harder, J. X. Hu, W. M. Leevy, J. Pajewska, R. Pajewski, M. E. Weber, Bioorg. Med. Chem. 2004, 12, $1291-1304$.

[6] a) S. Terrettaz, M. Mayer, H. Vogel, Langmuir 2003, 19, 5567-5569; b) G. Das, P. Tulukda, S. Matile Science 2002, 298, 1600-1602; c) S. Litvinchuk N. Sorde, S. Matile, J. Am. Chem. Soc. 2005, 127, 9316-9317.

[7] E. Gouaux, J. Struct. Biol. 1998, 121, 110-122.

[8] T. W. Greene, P. G. M. Wuts, Protective Groups in Organic Synthesis. 3rd ed., Wiley Interscience, New York, 1999.

[9] a) M. Mayer, J. K. Kriebel, M. T. Tosteson, G. M. Whitesides, Biophys. J. 2003, 85, 2684-2695; b) C. Schmidt, M. Mayer, H. Vogel, Angew. Chem 2000, 112, 3267-327; Angew. Chem. Int. Ed. 2000, 39, 3137-3140.

[10] The increase in conductance in the presence of $\mathrm{HCl}$ is due to the higher permeability of protons through gramicidin channels compared to potassium ions.
[11] Over the course of the reaction, we observed an intermediate current state of $17.9 \mathrm{pA}$, which presumably arose from the conversion of $\mathbf{1}$ to an intermediate of the reaction (e.g., the carbamic acid) that converts more slowly to product 2 . The observed current at $17.9 \mathrm{pA}$ might arise from a combination of indistinguishable conductance states generated from this intermediate of the reaction and/or asymmetric gramicidin channels formed from this intermediate and 2. Indistinguishable conductance states between symmetric and asymmetric gramicidin A channels have been previously reported in ref. [1d].

[12] W. Kirmse, Angew. Chem. 1976, 88, 273-283; Angew. Chem. Int. Ed. Engl. 1976, 15, 5, 251-261.

[13] For both of the reactions we describe in this work, the final products are the same regardless of whether the synthetic transformations occur while the peptides are in the membrane or in the aqueous phase. Although the order in which the reagents are added to the reaction vessels will not change the final products of the reactions, it is possible that the reaction rates are influenced by the local environment of the peptide. Therefore the observed kinetics of the reactions might depend on the order in which the reagents are added to the bilayer setup.

[14] a) K. Lee, V. Dzubeck, L. Latshaw, J. P. Schneider, J. Am. Chem. Soc. 2004, 126, 13616-13617; b) S. A. McFarland, N. S. Finney, J. Am. Chem. Soc. 2002, 124, 1178-1179; c) J. V. Mello, N. S. Finney, J. Am. Chem. Soc. 2005, 127, $10124-10125$; d) M. S. Tremblay, D. Sames, Org. Lett. 2005, 7, 2417-2420; e) R. Moreira, M. Havranek, D. Sames, J. Am. Chem. Soc. 2001, 123, 3927-3931; f) J. J. Lavigne, E. V. Anslyn, Angew. Chem. 2001, 113, 3212-3225; Angew. Chem. Int. Ed. 2001, 40, 3118-3130; g) K. Rurack, U. Resch-Genger, Chem. Soc. Rev. 2002, 31, 116-127.

[15] L. K. Mahal, K. J. Yarema, C. R. Bertozzi, Science 1997, 276, 1125-1128.

Received: November 16, 2005

Published online on January 30, 2006 